\title{
Aspectos de la personalidad de Rufino José Cuervo
}

Fernando Rodríguez-Izquierdo y Gavala

La figura de Rufino José Cuervo, de ordinario silenciada o tratada 'marginalmente en los manuales de historia de la lingüística, viene hoy a ocupar nuestra atención, aspirando a conseguir de nuestro reconocimiento el lugar señero que le corresponde dentro de la lingüística hispánica.

Vivimos una época en que se están realizando los preparativos de la celebración del quinto centenario del descubrimiento de América, y, olvidados y lejanos los antiguos motivos de disensión entre las que fueron provincias de ultramar y la metrópoli, el clima es de fraternidad y unión en espíritu y cultura. Esa unión que en su aspecto linguiístico fue para Rufino José Cuervo la causa de una firme vocación científica, e incluso diríamos que la razón de su vida.

\section{Semblanza biográfica}

Recordemos que Rufino José Cuervo nació en Bogotá el día 19 de Septiembre de 1844, y murió en París el 17 de Julio de 1911. Como Andrés Bello, su gran predecesor entre los lingüistas hispanoamericanos, fue hombre de formación autodidacta, «cosa que no pođía sorprender a nadie -en expresión de Rudolf Lenz ${ }^{1}$, ya que no había ni hay hasta hoy, en cuanto yo sepa, ninguna Universidad ni establecimiento parecido en América latina en que se enseñara filología románica, con excepción del Instituto Pedagógico de Chile». Y hemos de notar que dicho Instituto Pedagógico, aunque

1 «Un comentario de Rudolf Lenz sobre la 4" edición de las Apuntaciones», en SCHÜTZ, Günther: Epistolario de Rufino José Cuervo con Filólogos de Alemania, Austria y Suiza (obra en dos tomos) Publicaciones del Instituto Caro y Cuervo. Bogotá, 1976, t. II, p. 205 (Citaremos Ep. A., y a continuación el ordinal romano del tomo, y el número de página). El comentario de Lenz es de 1904; la $4^{\mathbf{a}}$ ed. de Apuntaciones es de 1885. Véase también MARTÍNEZ, Femando Antonio y TORRES QUINTERO, Rafael: Rufino José Cuervo. ICC (= Instituto Caro y Cuervo) Bogotá, 1954, pp. $72-73$ (Citaremos MTZ., seguido del número de página). 
deseado y propuesto desde 1842, no inició sus tareas sino hasta el día 1 de agosto de $1889^{2}$, cuando Cuervo estaba ya maduramente formado.

Dotado de escasa formación secundaria y ninguna universitaria ${ }^{3}$, Rufino José Cuervo se procuró, como instrumento de trabajo -y animado en el empeño por su hermano Ángel- el conocimiento de las tres lenguas más importantes para la ciencia de entonces: el inglés, el francés y el alemán; y a través de ellas estudió la historia de unas veinte lenguas indoeuropeas ${ }^{4}$. Pronto entró en contacto con la linguiística alemana. Según Boris de Tannenberg, que lo conoció personalmente por más de treinta años, el talento filológico de Cuervo se despertó sobre todopor la Gramática comparada de Bopp, «que poseyó a fondo» ${ }^{5}$. Ya en la primera edición de sus Apuntaciones críticas al lenguaje bogotano, que Cuervo vio en la imprenta con solo veintitrés años, en 1867 (fue publicada en 1872), cita él dicha obra de Bopp y dos más del mismo autor, y también obras de Pott, Max Müller y otros filólogos alemanes. En carta a Pott de 1876, publicada en el bien elaborado Epistolario de Rufino José Cuervo con Filólogos de Alemania, Austria y Suiza ${ }^{6}$, Cuervo manifiesta conocer, junto a la Gramática comparada de Bopp, las Investigaciones etimológicas del mismo Pott, «de suerte -declara D. Rufino en dicha carta- qụe Ud. ha alimentado en mí la afición a los estudios filológicos, y a Ud. le debo mucho de lo poco que en este ramo se me alcanza».

Cuando, en 1878, Rufino José Cuervo viaja a París con su hermano Ángel para visitar la Exposición Industrial -con vistas a mejorar un negocio familiar de producción de cerveza- y eń dicho año y el siguiente realiza una gira a diecisiete países europeos, el joven filólogo procura ampliar sus fondos bibliográficos, y también trabar contacto con lingüistas a los que conocía por sus escritos. Cuervo visitó en Halle a Pott, «viejo muy amable -contaría después Cuervo- que me obligó a hacerle la tertulia en latín» ${ }^{7}$. Encuentro este sumamente significativo, por ser Pott un autor que tanto había de influir en las ideas de Cuervo sobre las perspectivas de unidad, 0 -mejor dicho-de distanciamiento del castellano de América con respecto al peninsular.

Desde 1882, tras una estancia de tres años en Bogotá, Cuervo se instala en París para seguir su vocación científica. Su amigo Ezequiel Uricoechea, su primer maestro de alemán, lo animó a tomar esta decisión ${ }^{8}$ Rodolfo Lenz, en carta a Cuervo de $1901^{9}$, habla de «los conocimientos filológicos que tan fácilmente se pueden adquirir en las Universidades francesas y alemanas, pero que no se enseñan en Sudamérica ni tampoco en España». El mismo Cuervo en su artículo «El castellano en América» (1910) ${ }^{10}$ se

${ }^{2}$ Ep. A. I, 502.

${ }^{3}$ Ep. A., I, 56.

${ }^{4}$ Ep. A. I, 43-44.

${ }^{5}$ Citado en Ep. A. I, 57-58.

${ }^{6}$ Véase la referencia completa en nota ${ }^{1}$. Ep. A. I, 195.

${ }^{7} M T Z ., 100$.

${ }^{8} M T Z ., 90$.

${ }^{9}$ Ep. A. I, 549.

${ }^{10}$ Articulo que se encuentra en: CUERVO, Rufino José: El castellano en América. Editor: «El Ateneo». Buenos Aires, 1947, p. 57 (Citaremos Cast. Am., seguido del número de página). 
expresaría así, dirigiéndose a D. Juan Valera enmedio de la célebre polémica sobre la unidad del español: «Yo lamento también como el que más, y sin poderlo remediar, que si en América quiere uno estar al tanto del progreso científico y literario, desde la gramática hasta la medicina, la astronomía o la teología, no se le ocurra acudir a los libros españoles, y que si tiene los recursos necesarios para trasladarse a las universidades europeas, no escoja las de Madrid o Salamanca».

En París vivirá Cuervo cerca de treinta años dedicado a revisar y ampliar las sucesivas ediciones de las Apuntaciones, a escribir diversos artículos -hoy reunidos en las obras Disquisiciones de Filología Castellana ${ }^{11}$ y El Castellano en América ${ }^{12}$, y sobre todo a la magna obra del Diccionario de construcción y régimen de la lengua castella$n a^{13}$. Para este trabajo se encuentra prácticamente solo ${ }^{14}$ y con recursos exiguos ${ }^{15}$, situación comparable a la de la elaboración de las tres primeras ediciones de las Apuntaciones, en Bogotá, cuando «sobre los costales (de lúpulo y cebada) aguardan abiertos los libros, y ordenados los apuntes» ${ }^{16}$.

Su dedicación a la Filología en París le ganó el apelativo de «el cenobita parisiense» ${ }^{17}$. Esto no impedirá que el filólogo alemán Hans Rheinfelder (1898-1971) diga de él a título póstumo, al juzgar el tercer tomo de su Epistolario: «Pasan delante de nosotros las vivencias de una generación en su historia cultural europea y latinoamericana de esa época. El gran filólogo Cuervo está dentro de la vida, con los pies firmes ${ }^{18}$. En 1910, un año antes de su muerte, Cuervo recibe el nombramiento de Doctor Honoris Causa por la Universidad de Berlín. En el diploma de investidura se habla de él como de «bogotano hecho ahora parisiense» («bogotano nunc parisiensi») ${ }^{19}$.

Sobre esta figura internacional de Cuervo podríamos desarrollar varios temas: su concepto de lengua y de norma, su actitud ante la Real Academia de la Lengua, su visión

${ }^{11}$ CUERVO, Rufino José: Disquisiciones sobre Filología Castellana. «El Ateneo». Buenos Aires, 1948. (Citaremos Disq., seguido del número de página).

${ }^{12}$ Véase nota10.

${ }^{13}$ CUERVO, R. J.: Diccionario de construcción y régimen de la lengua castellana. Primera edición: A. Rogery F. Chernoviz, Libreros Editores. París. T. I. (A-B) 1886; T-II (C-D) 1893. (Citaremos Dic.c.r.,seguido del número romano de la página de la Introducción, y por la edición facsimilar del ICC de Bogotá, 1953).

${ }^{14}$ Según Boris de Tannenberg (Ep. A. I, 428, nota 11) Cuervo solo contó con dos colaboradores jóvenes que le copiaban pasajes y se los clasificaban por orden alfabético a medida que él los anotaba en sus lecturas. Mientras que Littré, por ejemplo, tuvo siete colaboradores asiduos, y muy bien remunerados por Hachette y $\mathrm{C}^{\mathbf{a}}$. También son escasas -unas cincuenta, precisará Cuervo- las citas que recibe como aportaciones de otros. Véase además cómo se expresa Cuervo en el mismo Dic.c.r., XLIII: «Si bien pudiera desearse que fuese aún mayor el número de autores estudiados para nuestra obra, quien considere cuánto tiempo y cuán fatigosa atención se requiere para esta faena, no exigirá más a una sola persona».

${ }^{15}$ Dic. c. r., XLIV.

${ }^{16}$ Cast. Am. Tomado de la Introducción de Rodolfo M. Ragucci, S. S.

${ }^{17}$ Cas. Am., 24 de la Introducción de Ragucci.

${ }^{18}$ Ep. A. II, 241. Traducción en II, 359. El III tomo del Epistolario de Cuervo es el que recoge su correspondencia con Luis María Lleras y otros amigos y familiares. Edición, introducción y notas de Guillermo Hemández Alba. Publicaciones del ICC. Bogotá, 1970.

${ }^{19}$ Ep. A. II, lámina XLIII, tras pág. 240. 
del problema de la unidad del español, su propia personalidad humana y científica... Podríamos acumular merecidos elogios que otros han hecho de él. Tal programa desbordaría los límites de este estudio, y por ello vamos a reducirnos a algunas consideraciones brotadas al hilo de la lectura del Epistolario de Schütz antes citado ${ }^{20}$, consideraciones que irán tocando los puntos recién mencionados, sin pretender en ningún momento dar un tratamiento exhaustivo de los mismos.

\section{Concepción de la lengua, y de la ciencia lingüística}

ElProfesor Günter Schütz nos dice en la Introducción general de dicho Epistolario que Cuervo recibió influencia de los Neogramáticos y «también de Schuchardt, su mayor amigo alemán, quien nadó frecuentemente contra esta corriente. Don Rufino murió antes de que hubieran podido llegarle las nuevas ideas del suizo Saussure» ${ }^{21}$. Es cierto que tanto Saussure como Cuervo vivirían en París durante los años comprendidos entre 1882 y 1891 , que ocupan gran parte del llamado "período parisiense» de Saussure ${ }^{22}$, pero también hemos de recordar que durante este período el profesor ginebrino cultiva el comparatismo, y aún no revela las ideas que más tarde -entre 1907 y 1911- ha de desarrollar en Ginebra en tomo a la Linguiística General, ideas que sus alumnos publicarán en forma de libro -el célebre Cours de linguistique générale-en 1916, y que le darán fama internacional como "padre del estructuralismo lingüístico» a mediados del siglo $\mathrm{XX}^{23}$.

A pesar de ello nos parece descubrir en Cuervo ciertas ideas que podríamos calificar de «saussirianas» o de «presaussirianas».

Cuervo equiparaba con frecuencia la lengua a un organismo natural ${ }^{24}$, situándose así como punto de partida en la concepción de Schleicher. «El lenguaje no es ya aquel mecanismo inerte y sin vida perennemente sujeto a fórmulas inmutables; todo se muda en él» ${ }^{25}$-nos dice en la Introducción a las Notas con que amplió la Gramática castellana de Bello. Y aunque Cuervo no citó en ninguna ocasión a Humboldt ni a Vossler ${ }^{26}$, la

${ }^{20} \mathrm{Ep}$. A.: presentado a la altura de la nota 6, aunque en realidad venimos usando material de este Epistolario desde la nota 1.

${ }^{21}$ Ep. A., I, 66. Martín Franzbach deduce de la lectura del II tomo del Epistolario (Epistolario de Rufino José Cuervo y Hugo Schuchardt. Edición, introducción y notas de Dieter Bross. ICC. Bogotá, 1968) que Shuchardt influyó sobre Cuervo en el sentido de hacerlo distanciarse de las teorías neogramáticas. Ep. A. II, 239. Trad. en II, 357. 13.

${ }^{22}$ MOUNIN, Georges: Saussure, presentación y textos. Ed. Anagrama. Barcelona, $3^{\mathbf{2}}$ ed. 1971, pp. $12-$

${ }^{23}$ Hacia 1956, según puntualiza Mounin en o. c. en la nota anterior, p. 8.

${ }^{24}$ MTZ, 111. También usa Cuervo la expresión «vida y crecimiento de una lengua» (Dic. c.r., XXII), «vida del lenguaje* -en CUERVO, R. J.: Apuntaciones críticas sobre el lenguaje bogotano. ICC. Bogotá, 9 a ed. 1955, p. 46 (Citaremos Apunts., y número de página)-, «vida de la lengua» (Apunts., 23), etc.

${ }^{25}$ BELLO, Andrés, y CUERVO, R. J.: Gramática de la Lengua Castellana. Ed. Sopena Argentina. Buenos Aires, $8^{\mathbf{a}}$ ed. 1970, p. 405 (Citaremos Gram., y número de página). Apunts., 23.

${ }^{26} \mathrm{Ep}$. A. I, 67. 
influencia idealista es también patente en su obra. Nunca la lengua llega a ser para él una abstracción o un esquema rígido que prescinda de los individuos o pueda separarse de ellos ${ }^{27}$. Hay siempre en el hablante un «instinto de raza» ${ }^{28}$ que lo condiciona mucho más que una serie de preceptos apriorísticos, y constituye en realidad el instinto transformador del idioma, en la causalidad de los fenómenos lingüísticos no intervienen -como algunos habían pretendido- solo leyes físicas. Junto a las causas o leyes fonéticas cuentan las psicológicas ${ }^{29}$.

«El lenguaje es cualidad del hombre; y siendo elemento a un mismo tiempo y producto de la sociabilidad humana, instrumento de una voluntad libre y de una razón inteligente, está expuesto a muy varias influencias, que ora apresuran, ora retardan o detienen los cambios de la parte que en él lleva carácter material, o introducen otros inesperados» ${ }^{30}$. Por otra parte, Cuervo no desdeña el uso de expresiones netamente idealistas, como: «genio del idioma» ${ }^{31}$; «el espíritu de nuestros mayores» donde «sorprendemos los impulsos que prepararon los cambios subsiguientes» 32 ; «el individuo ha de seguir la corriente de la lengua» ${ }^{33}$; «espíritu de la nación» ${ }^{34}$; «nada, en nuestro sentir, simboliza tan cumplidamente a la patria como la lengua» ${ }^{35}$.

Apreciamos pues que Cuervo alcanza así una posición de madurez y síntesis entre el positivismo y el idealismo, como creemos que alcanzó Saussure con sus célebres dicotomías Habla/Lengua, Individuo/Sociedad. Como el maestro suizo, Cuervo atribuyó también una gran importancia a la psicología y sus leyes en la formación de la gramática ${ }^{36}$ hasta el punto de ser considerado por Ragucci «el mayor psicólogo de la lengua» ${ }^{37}$. Como también Saussure, considera la lengua como una abstracción que se actualiza en parte en los individuos ${ }^{38}$. Como el ginebrino, se preocupó por la constitución

${ }^{27}$ MTZ., 143. Dic.c.r., XXIII.

${ }^{28}$ Apunts., 56.

${ }^{29}$ Apunts., 49.

${ }^{30}$ Dic.c.r., XXIII.

${ }^{31}$ Dic.c.r., XXIX. «Genio de la lengua»: ibid., XL.

${ }^{32}$ Dic.c.r., XLIII.

${ }^{33}$ Dic.c.r., XXXIX.

${ }^{34}$ Dic.c.r., XL.

${ }^{35}$ Apunts., 6.

${ }^{36}$ Dic.c.r., XXXVIII. Apunts., 48. Gram., 406-407. Cast. Am., 16-17 (de la Introd. de Ragucci). González de la Calle insiste en la importancia que tiene para la concepción linguística de Cuervo el conocimiento de la psiquis individual y de la psiquis colectiva. GONZÁLEZ DE LA CALLE, Pedro Urbano: Contribución al estudio del bogotano. ICC. Bogotá, 1963, p. 23. Recordemos que, para Saussure, la Semiología (ciencia que alberga a la Linguística) debe ser "parte de la psicología social, y por consiguiente de la psicología general». SAUSSURE, Ferdinand de: Curso de Lingüística General. Ed. Losada. Buenos Aires, $6^{2}$ ed. 1967, p. 60 (Citaremos Curso, y núm. de pág.).

${ }^{37}$ Cast. Am., 19 (de la Introd. de Ragucci).

${ }^{38}$ Apunts., 20-21 y 45. SAUSSURE: «La lengua existe en la colectividad en la forma de una suma de acuñaciones depositadas en cada cerebro, más o menos como un diccionario...» Curso, 65. 
de la lingüística como ciencia autónoma, no subordinada a la filología ${ }^{39}$ :

«Por un instinto fatal y conducidos por el sentido común -el genio de la humanidad, como se le ha llamado-, obedecen los pueblos en la formación de sus vocablos, en la generación de las acepciones y en la armazón de las frases, a leyes admirables, (...) que (...) resultan regir las lenguas más distintas, y constituyen con sus importantes aplicaciones la ciencia del lenguaje, o sea la lingüística, base verdadera de la gramática general y criterio segurísimo, superior en cierto sentido a la autoridad y su limitador, aunque también se le subordina en ocasiones; pero por punto general se dan la mano y mutuamente se sustentan ${ }^{40}$.

También nos parece Cuervo próximo a Saussure cuando, desarrollando el concepto de lengua, aboca en el de estructura: «la lengua, con sus principios fonéticos y morfológicos, con su sintaxis y semasiología peculiares, es atributo propio de la nacionalidad, y superior por consiguiente al individuo, quien, por descuido u obedeciendo a principios falsos, puede caer en error; y con la autoridad de la lengua misma, en cuanto se haya estudiado de raíz en todas las manifestaciones de su desenvolvimiento histórico, no solo es lícito sino forzoso desaprobar toda práctica que rompa con las leyes que rigen su estructura» ${ }^{41}$.

\section{Su opinión sobre la Real Academia Española de la Lengua}

Ya un decenio antes de la aparición del Diccionario de construcción y régimen, Cuervo había sido nombrado correspondiente extranjero de la Real Academia Española (12 de Julio de 1875$)^{42}$.

En la biblioteca de Cuervo se encontraban todas las ediciones del Diccionario de la Real Academia Española aparecidas hasta la fecha de su muerte, desde el primer Diccionario de Autoridades hasta la edición $\mathrm{n}^{\mathrm{Q}} 13$, de $1899^{43}$. Cuervo reconoce que el Diccionario académico es «base indispensable» de las Apuntaciones ${ }^{44}$, y como tal tiende a defenderlo ya desde la primera edición de esta obra ${ }^{45}$. La Academia, por su carácter secular y corporativo, no se deja llevar por las modas, resiste fácilmente a las exageraciones de cualquier escuela, y «tiene en sí el equilibrio de conocimientos de que rarísima vez sería capaz un particular. Todo esto dará siempre al Diccionario de la

${ }^{39}$ Interés en que coincide también con Ascoli, Schuchardt y Meyer-Lübke, según nos recuerda Schülz en $E p$. A., I, 679-680. En cuanto a Saussure, véase Curso, 47, donde afirma que la filología es netamente distinta de la linguística, a pesar de sus puntos de contacto.

${ }^{40}$ Apunts., 14.

${ }^{41}$ Dic.c.r., XXXVIII. Aunque es sabido que Saussure usa casi con exclusividad el término de «sistema» -sobre el de «estructura»-, es ya un hecho indiscutible su concepción estructuralista de la lengua.

${ }^{42}$ Ep. A. II, 227, nota 4.

${ }^{43}$ Ep. A. I, 392, nota 40; y 427, nota 6.

${ }^{44}$ Apunts, 66.

${ }^{45}$ Ep. A., I, 394: Introducción a la correspondencia Cuervo-Foerster. 
Academia una superioridad incontestable sobre otros libros análogos» ${ }^{46}$. También en el Prólogo de Apuntaciones, Cuervo defiende el Diccionario académico -junto al de D. Vicenta Salvá- como representante del uso lingüístico que hace ley, el uso -como Cuervo gusta de calificar- «respetable, general y actual» ${ }^{47}$.

Sin embargo, no es Cuervo autor que en momento alguno sienta subordinada su independencia científica a ningua autoridad externa. Las obras de la Academia, humanas al fin, nunca están a salvo de los «reparos» ${ }^{48}$ que les dirige el filólogo. No es de extrañar que las alabanzas que Cuervo hace del Diccionario de la Real Academia vayan a veces acompañadas de reservas. Precisamente el hecho de que el Diccionario académico haya sido elaborado entre muchos ${ }^{49} \mathrm{y}$ ofrezca a veces acuerdos de comisiones no siempre formadas por los más competentes, acuerdos aprobados a veces «ligeramente por aclamación» ${ }^{50}$ induce a Cuervo a declarar que «el Diccionario de la Academia, con sus defectillos, es todavía el mejor que tenemos» ${ }^{51}$, y también a contraponer siempre a su criterio de autoridad el de la investigación lingüística. Cuervo denuncia la actitud de «respeto supersticioso» ${ }^{52}$ ante la Gramática y el Diccionario de la Academia, y la atribución de «infalibilidad absoluta» ${ }^{53}$ frecuentemente otorgada al Diccionario. En frase que podemos tomar como resumen compendioso de su pensamiento, Cuervo aplica al Diccionario -y creemos que, por extensión, a la Academia- el dicho de Fígaro: «El Diccionario de la lengua tiene la misma autoridad que todo el que tiene razón, cuando él la tiene» ${ }^{54}$.

Algunos de sus contemporáneos fueron más lejos. Wendelin Foerster comunica a Cuervo, en carta de 1903, al paso que lo anima a escribir una Gramática histórica española: «el miserable Diccionario de la Academia Española, que con cada edición degenera más, es un verdadero horror» ${ }^{55}$. Lenz detectaba «millares de disparates» ${ }^{56}$ en el Diccionario de la Real Academia.

Cuervo mismo, que se había situado al margen de decisiones académicas en su estudio sobre los pronombres átonos ${ }^{57}$, critica sin paliativos las preferencias cultas y la

${ }^{46}$ Dic.c.r., XLII. Análogas ideas en «Observaciones sobre el Diccionario de la Real Academia Española», Disq., 125, donde Cuervo alaba la «prudente cautela» de la Real Academia.

${ }^{47}$ Apunts. 11, 13. MTZ. comenta estos calificativos en p. 125.

${ }^{48}$ Dic.c.r., XLII.

49 «Carta a Don Camilo Ortúzar», Disq., 161.

${ }^{50}$ Apunts., 66. Es notable la indignación de que da muestras Cuervo, en una de las fichas de su registro bibliográfico, cuando descubre en dos sucesivas ediciones del Diccionario de la Real Academia «las mismas erratas, disparates y desaliños». Ep. A. I, 392-393.

51 «Carta a D. Camilo Ortúzar», Disq., 164.

${ }^{52}$ Apunts., 55, 64.

${ }^{53}$ Disq., 161. Véase también Ep. A., I, 393, a la altura de la nota ${ }^{46}$.

${ }^{54}$ Apunts., 55.

${ }^{55}$ Ep. A. I, 425. Trad. en II, 275.

${ }^{56}$ Ep. A. I, 516.

57 «Los casos enclíticos y proclíticos del pronombre de tercera persona en castellano» (1895), Disq., 297369. Ep. A., I, 725-727, y 732. 
consiguiente animadversión a formaciones populares de que da muestras la Academia en su Diccionario ${ }^{58}$ : «la Academia patrocina pedanterías como cañafistula, malva rósea, substancioso ${ }^{59}$. Nada debe pues extrañarnos que en su correspondencia privada, en carta a Benigno Barreto de 5 de julio de 1901, Cuervo se muestre escéptico respecto a la labor, no precisamente de la Academia Española, sino de «las Academias» en general. Hablando de D. Juan Valera, su antagonista en la disputa sobre el porvenir del español de América, Cuervo manifiesta: «no le conviene una polémica que sin duda suscitará en muchos el espíritu de rebeldía que momentáneamente está adormecido gracias a las Academias, a los Congresos, y otros medios inventados para halagar la vanidad de los americanos» ${ }^{60}$.

En resumidas cuentas, Cuervo, algo descontento con el rendimiento de la Academia en su tiempo, propone a las Academias como programa de actuación que no se contenten con ser cuerpos pasivos, meros registradores y sancionadores de cambios. «Ellas -las Academias- deben influir también, científicamente (me permito llamar la atención sobre este adverbio tan significativo de Cuervo) en la dirección del uso y en el movimiento de la lengua» ${ }^{61}$.

\section{Observaciones finales:}

No podemos internamos, por más que sea apasionante, en el tema del debate que mantuvo Cuervo con D. Juan Valera sobre el porvenir del castellano en América. En nuestra opinión, se trata de una discusión extralingüística por la parte que en ella juega el literato español, llevado de argumentos sentimentales y subjetivos, e inclinado por ello a distorsionar las afirmaciones de su oponente. Cuervo se colocó desde el principio en una perspectiva netamente científica, sugerida -según él mismo confiesa- por cierta frase de una carta que Pott le escribió (1877) al agradecerle el envío de la segunda edición de las Apuntaciones. Pott opinaba que el castellano seguiría la suerte de latín en cuanto a fragmentación dialectal, por no poder escapar al destino que imponen las leyes generales de la naturaleza. «Por ese tiempo-comenta Cuervo en 1903-no tenía yo mayor conocimiento del estado del castellano en América, fuera de mi patria, ni había meditado sobre el particular; así que me pareció infundado el pronóstico» ${ }^{62}$.

Sin embargo, es sabido cómo Cuervo acogió con los años la predicción de Pott, y en la carta-prólogo al poema «Nastasio» (1899) de D. Francisco Soto y Calvo, incluyó estas palabras que desencadenaron la polémica: «Estamos pues en vísperas (que en la

\footnotetext{
${ }^{58}$ Apunts., 29-30, 60 y 66.

${ }^{59}$ Apunts., 64, nota 47.

${ }^{60}$ Ep.A. I, 531; véase nota ${ }^{96}$.

${ }^{61}$ «Observaciones sobre el Diccionario de la Real Academia Española», Disq., 126.

${ }^{62}$ Ep. A. I, 189-191.
} 
vida de los pueblos pueden ser bien largas) de quedar separados, como lo quedaron las hijas del Imperio Romano» ${ }^{63}$.

Este panorama fatalista (que Cuervo ve sobre un trasfondo de siglos, aspecto temporal este muy importante, que sufrió la más burda tergiversación por parte de Valera $^{64}$ ), creemos que influyó positivamente en el enfoque de Apuntaciones, a medida que esta obra se iba reeditando. De ser una obra nacida con el propósito normativo de corregir errores y solecismos, muy acorde con el ambiente sociocultural de Bogotá durante la infancia de Cuervo y aun antes ${ }^{65}$, Apuntaciones se fue configurando como una monumental primera piedra de la lingüística hispanoamericana ${ }^{66}$, como un verdadero instrumento de hermandad y unión lingüística entre el castellano peninsular de España y el continental de América. Este ideal, que Cuervo concibió de algún modo como misión de su vida -«el hermanamiento (usando su propia expresión) de las naciones hispanoamericanas ${ }^{67}$ - era sin duda el que con más urgencia lo comprometía al estudio de la lengua.

Es significativa a este respecto la frase que Cuervo escribió en el Prólogo destinado a la sexta edición de Apuntaciones (París, 1914), pero que no fue publicado sino en la séptima (Bogotá, 1939) ${ }^{68}$ y no se encuentra en el Prólogo de la primera edición: «De aquí (de los beneficios derivados de la unidad lingüística) la conveniencia de conservar en su integridad la lengua castellana, medio providencial de comunicación entre tantos millones de hombres que la hablan en España y en América» ${ }^{69}$. La fraseología recuerda unas hermosas palabras de Andrés Bello, enmarcadas en el Prólogo de su Gramática ${ }^{70}$.

El tema es aún de actualidad; en 1982, el entonces Presidente de la Real Academia Española de la Lengua, D. Pedro Laín Entralgo, dijo en una declaración -convertida por un diario madrileño en «La Frase» del día ${ }^{71}$-: «No peligra la unidad del idioma español».

Efectivamente, hoy día en que presenciamos un notable auge en las comunicaciones de todo tipo -literatura, arte, cultura, comercio- entre España e Hispanoamérica, parece muy remoto el peligro de escisión que presintiera Cuervo.

No obstante, y paradójicamente, creemos que pesa en esta perspectiva actual algo más optimista, toda la vida y la obra de Cuervo, dedicadas a la unidad de la lengua. Nos sentimos deudores de su sabia investigación, que encontró en la historia de la lengua la

${ }^{63}$ Cast. Am, 36.

${ }^{64}$ Los principales documentos - artículos o cartas abiertas de Cuervo y Valera- para juzgar esta polémica, se encuentran en Cast. Am., 33-129.

${ }^{65}$ MTZ., 36-44. Véase también el Prólogo de la $1^{\text {a }}$ ed. de Apunts., 6.

${ }^{66}$ Apunts., VI.

${ }^{67}$ Apunts., 6. Véase tb. p. 7: «rotas las antiguas ataduras, unos y otros son pueblos hermanos».

${ }^{68}$ Estos datos, en Apunts., 3-4.

${ }^{69}$ Apunts., 20.

${ }^{70} \mathrm{Gram}$., 24. Las palabras de Bello son las siguientes: «Juzgo importante la conservación de la lengua de nuestros padres en su posible pureza, como un medio providencial de comunicación y un vínculo de fratemidad entre las varias naciones de origen español derramadas sobre los dos continentes».

${ }^{71}$ Diario Ya (Madrid), 4 de Diciembre de 1982. 
síntesis feliz -expresada con palabras de Fernando Antonio Martínez ${ }^{72}$ - de lingüística y filología, lengua literaria y lengua popular, tradición y actualidad, pasado y presente». El ejemplo de Rufino José Cuervo nos estimula, nos alienta y nos obliga. 